\title{
Advances in Molecular Serotyping and Subtyping of Escherichia coli ${ }^{\dagger}$
}

\author{
Pina M. Fratamico ${ }^{1 *}$, Chitrita DebRoy², Yanhong Liu', David S. Needleman', \\ Gian Marco Baranzoni ${ }^{1}$ and Peter Feng ${ }^{3}$ \\ 'Eastern Regional Research Center, Agricultural Research Service, United States Department of Agriculture, Wyndmoor, PA, \\ USA, ${ }^{2}$ Department of Veterinary and Biomedical Sciences, Pennsylvania State University, University Park, PA, USA, \\ ${ }^{3}$ Division of Microbiology, U.S. Food and Drug Administration, College Park, MD, USA
}

OPEN ACCESS

Edited by:

Feng Gao,

Tianjin University, China

Reviewed by:

Andrea Isabel Moreno Switt, Universidad Andrés Bello, Chile Séamus Fanning,

University College Dublin, Ireland

*Correspondence:

Pina M. Fratamico

pina.fratamico@ars.usda.gov

Specialty section:

This article was submitted to

Evolutionary and Genomic

Microbiology,

a section of the journal

Frontiers in Microbiology

Received: 26 February 2016

Accepted: 18 April 2016

Published: 03 May 2016

Citation:

Fratamico PM, DebRoy C, LiuY,

Needleman DS, Baranzoni GM

and Feng $P$ (2016) Advances

in Molecular Serotyping

and Subtyping of Escherichia coli.

Front. Microbiol. 7:644.

doi: 10.3389/fmicb.2016.00644
Escherichia coli plays an important role as a member of the gut microbiota; however, pathogenic strains also exist, including various diarrheagenic E. coli pathotypes and extraintestinal pathogenic E. coli that cause illness outside of the Gl-tract. E. coli have traditionally been serotyped using antisera against the ca. 186 O-antigens and 53 $\mathrm{H}$-flagellar antigens. Phenotypic methods, including bacteriophage typing and $\mathrm{O}$ - and $\mathrm{H}$ - serotyping for differentiating and characterizing $E$. coli have been used for many years; however, these methods are generally time consuming and not always accurate. Advances in next generation sequencing technologies have made it possible to develop genetic-based subtyping and molecular serotyping methods for E. coli, which are more discriminatory compared to phenotypic typing methods. Furthermore, whole genome sequencing (WGS) of $E$. coli is replacing established subtyping methods such as pulsedfield gel electrophoresis, providing a major advancement in the ability to investigate food-borne disease outbreaks and for trace-back to sources. A variety of sequence analysis tools and bioinformatic pipelines are being developed to analyze the vast amount of data generated by WGS and to obtain specific information such as $\mathrm{O}$ - and $\mathrm{H}$-group determination and the presence of virulence genes and other genetic markers.

Keywords: Escherichia coli, molecular serotyping, subtyping, detection, identification, whole genome sequencing, O-group, H-type

\section{INTRODUCTION}

Escherichia coli strains are commensal organisms that are part of the normal intestinal microflora of humans and other mammals. The traditional method for identifying E. coli uses antibodies to test for surface antigens: the $\mathrm{O}$ - polysaccharide antigens, flagellar $\mathrm{H}$-antigens, and capsular $\mathrm{K}$-antigens (described below). There are currently $\sim 186$ different $E$. coli O-groups and $53 \mathrm{H}$-types, so serotyping is highly complex. There are also many pathogenic groups of $E$. coli that cause disease in humans and animals, including diarrheagenic E. coli and the extra-intestinal pathogenic E. coli (ExPEC) that cause illness outside of the GI-tract. Diarrheagenic E. coli that cause human illness have been classified based on specific sets of virulence genes they carry and the characteristics of the disease they cause (Kaper et al., 2004). These pathotypes include the enteropathogenic E. coli (EPEC), enterotoxigenic E. coli (ETEC), enteroinvasive E. coli (EIEC), enteroaggregative E. coli (EAEC), Shiga toxin-producing E. coli (STEC), diffusely adherent E. coli (DEAC), and

\footnotetext{
${ }^{\dagger}$ Mention of trade names or commercial products is solely for the purpose of providing specific information and does not
} imply recommendation or endorsement by the U.S. Department of Agriculture. 
adherent invasive E. coli (AIEC) that have been associated with Crohn's disease. There are also hybrid pathotypes, including the enteroaggregative hemorrhagic E. coli (EAHEC) that carry STECand EAEC-associated virulence genes. As an example, EAHEC serotype O104:H4, an EAEC that acquired the phage that carried the Shiga toxin gene of STEC, caused a large outbreak in 2011 associated with illness in over 3800 individuals and 54 deaths (Frank et al., 2011). Certain E. coli serotypes are often associated with specific pathotypes, such as STEC O157:H7 and O103:H21 (Kaper et al., 2004) that are important STEC, often referred to as enterohemorrhagic E. coli (EHEC). Therefore, pathogenic $E$. coli constitutes a genetically heterogeneous family of bacteria, and they continue to evolve.

Extra-intestinal pathogenic E. coli cause illness outside of the gastrointestinal tract, including urinary tract infections, meningitis, pneumonia, septicemia, and other types of infections (Russo and Johnson, 2003; Smith et al., 2007). ExPEC that cause illness in poultry are known as avian pathogenic E. coli (APEC). Avian colibacillosis caused by APEC is a major cause of morbidity and mortality associated with economic losses in the poultry industry throughout the world. The human gut is a reservoir for ExPEC that cause human illness. When ExPEC leave the GI tract and infect other parts of the body such as the urinary tract, the blood, or the lungs, illness results (Smith et al., 2007). Animals, particularly, poultry and poultry products (eggs), pork/pigs, and beef/cattle, and also companion animals may carry ExPEC, and thus, these pathogens may be acquired through the food supply, and zoonotic pathogens may also be acquired via contact with animals (Vincent et al., 2010; Nordstrom et al., 2013; Mitchell et al., 2015; Singer, 2015). Investigations of community-acquired UTI and outbreaks of UTI suggested common point sources, such as contaminated food products (Nordstrom et al., 2013). Indeed, high genetic similarity, including antibiotic resistance and virulence gene patterns, between APEC and ExPEC strains causing disease in poultry and humans, respectively, has been observed (Smith et al., 2007; Manges and Johnson, 2012). The ability to differentiate commensal E. coli from ExPEC and other pathotypes is important for risk assessment and epidemiological and ecological studies. However, a rapid and reliable typing/identification system or criteria that allows this type of discrimination and that also provides information on the organism's evolutionary history, fitness, and pathogenic potential has not yet been established. Determining whether an E. coli strain is an ExPEC and whether it is pathogenic is based on its source, O:K:H serotype, phylogenetic background, virulence factor profile, and experimental virulence in an animal model. ExPEC belong to specific phylogenetic groups (A, B1, B2, and D) determined based on multilocus enzyme electrophoresis, ribotyping, or by triplex PCR targeting the genes chuA and $y j a A$ and a particular DNA fragment known as TSPE4.C2. ExPEC strains belonging to phylogenetic groups B2 and D show higher virulence in humans (Clermont et al., 2000; Smith et al., 2007). It has become evident that certain ExPEC lineages or clonal groups are responsible for a large fraction of human extraintestinal E. coli infections, and these lineages are becoming increasingly multi-drug resistant (Smith et al., 2007; Manges and Johnson, 2012).
Rapid and accurate molecular methods are critically needed to detect and trace pathogenic E. coli in food and animals and for epidemiological investigations to enhance food safety and animal and human health, as well as to minimize the size and geographical extent of outbreaks. As opposed to traditional serotyping using antisera raised against the different E. coli Oand $\mathrm{H}$-types, molecular serotyping generally refers to geneticbased assays targeting O-group-specific genes found within the E. coli $\mathrm{O}$-antigen gene clusters and the $\mathrm{H}$-antigen genes that encode for the different flagellar types. Although determining the E. coli serotype could be considered a component of subtyping (differentiation beyond the species level), methods used for molecular subtyping such as pulsed-field gel electrophoresis (PFGE), multilocus sequence typing (MLST), and whole genome sequencing (WGS) generate a unique "fingerprint" of the bacterium that can be used in outbreak investigations and to determine the source of illnesses. There are many problems associated with traditional serotyping for determining the E. coli $\mathrm{O}$ - and $\mathrm{H}$-groups. It is costly, labor-intensive and time consuming, cross reactivity of the antisera with different serogroups occurs, antisera are available only in specialized laboratories, batch-to-batch variations in antibodies can occur, and many E. coli strains isolated from various sources are nontypeable (Lacher et al., 2014). Thus, molecular serotyping offers alternative methods for E. coli serotyping, and furthermore, they can be coupled with assays for specific virulence gene enabling the determination of $\mathrm{O}$ - and $\mathrm{H}$-group, pathotype, and the strain's pathogenic potential simultaneously.

\section{E. coli O-, K-, AND H-ANTIGENS}

The outer membrane of $E$. coli is composed of lipopolysaccharides (LPS) that includes lipid A, core oligosaccharides, and a unique polysaccharide, referred to as the $\mathrm{O}$-antigen. Loss of the $\mathrm{O}$-antigens results in attenuated virulence suggesting their importance in host-pathogen interactions (Sarkar et al., 2014). Based on the antigenic diversity among the different $\mathrm{O}$-antigens, they have been targeted as biomarkers for classification of E. coli since the 1940s (Kaufmann, 1943, 1944, 1947). Later, Ørskov et al. (1977) presented a comprehensive serotyping system for 164 E. coli O-groups and developed a typing scheme based on the presence of three principal surface antigens, $\mathrm{O}$-antigens, flagellar $\mathrm{H}$-antigens, and capsular $\mathrm{K}$-antigens. Since few laboratories had capabilities to type the $\mathrm{K}$ antigen, serotyping based on $\mathrm{O}$ and $\mathrm{H}$-antigens became the gold standard for $E$. coli typing. Currently, O-groups numbered O1-O188 have been defined, except for O31, O47, O67, O72, O94, and O122 that have not been designated (Ørskov and Ørskov, 1984; Scheutz et al., 2004), and four groups have been divided into subtypes O18ab/ac, O28ab/ac, O112ab/ac, and O125ab/ac, giving a total of 186 O-groups.

The conventional serotyping method is based on agglutination reactions of the $\mathrm{O}$-antigen with antisera that are generated in rabbits against each of the O-groups (Ørskov and Ørskov, 1984). The method is easy to carry out; however, it is 
laborious and error-prone, and thus, molecular methods are better alternatives for O-typing (Ballmer et al., 2007; Lacher et al., 2014). The genes that encode for O-antigens are located on the chromosome in a cluster designated as the $\mathrm{O}$-antigen gene cluster (O-AGC). These are flanked by two conserved sequences called JUMPstart, a 39 bp-element at the $5^{\prime}$ end (Hobbs and Reeves, 1994), which is downstream of galF (UTP-glucose-1-phosphate uridylyltransferase) and gnd (6phosphogluconate dehydrogenase) at the $3^{\prime}$ end. Analysis of the O-AGCs of all E. coli O-groups (Iguchi et al., 2015a; DebRoy et al., 2016) showed that the sizes of the O-AGCs and their gene content vary considerably, which results in the variability of $\mathrm{O}$-antigens. O-antigens are composed of 1025 repeating units of two to seven sugar residues and are processed by three mechanism of which the most common is Wzy ( $\mathrm{O}$ antigen polymerase) dependent, followed by an $\mathrm{ABC}$ transporter dependent system, and the third mechanism, which involves a synthase dependent pathway (Greenfield and Whitfield, 2012) by which the O-antigens are flipped across the outer membrane. The pathways for biosynthesis of the O-AGCs and assembly of O-antigens have been studied extensively (Samuel and Reeves, 2003). Each of the O-antigens that utilize Wzy-dependent pathway carries two unique genes $w z x$ (O-antigen flippase) and $w z y$ (O-antigen polymerase). Wzx proteins translocates the $\mathrm{O}$-units across the inner membrane, and Wzy polymerizes the O-antigen (Samuel and Reeves, 2003). For the ABC transporter-dependent pathway, wzm (O-antigen $\mathrm{ABC}$ transporter permease gene) and wzt (ABC transporter ATP-binding gene) are involved in O-AGC synthesis. The $\mathrm{O}$-AGCs are composed of nucleotide sugar biosynthesis genes that are involved in the synthesis of $\mathrm{O}$-antigen nucleotide sugar precursors, the glycosyl transferases that transfer the various sugar precursors to form the oligosaccharide, and the $\mathrm{O}$-antigen processing genes described above.

All of the O-AGC clusters have been sequenced, and sequence analyses revealed that some O-AGCs are $98-100 \%$ identical (Iguchi et al., 2015a; DebRoy et al., 2016) while others have point mutations or insertion sequences which causes these to type as different serogroups (Liu et al., 2008, 2015). Therefore, there is a need to resolve these discrepancies, merge or eliminate serogroups and to revise the $E$. coli serotype nomenclature (DebRoy et al., 2016). Furthermore, many of the E. coli O-AGCs have been found to be identical to those of other Enterobacteriaceae members such as Shigella and Salmonella (Wang et al., 2007). Out of 34 distinct Shigella O-antigens, 13 were unique to Shigella; however, the other 21 were also found in E. coli (Liu et al., 2008). Similarly, out of 46 O-AGCs of Salmonella, 24 of were found to be identical or closely related to E. coli O-antigens (Liu et al., 2014).

Serology has defined $53 \mathrm{H}$-flagellar antigens (Ørskov and Ørskov, 1984; Ewing, 1986) that are numbered from $\mathrm{H} 1$ to H56, but H-types 13, 22, and 50 are not in use (Ørskov et al., 1975; Centers for Disease Control and Prevention [CDC], 1999). Molecular H-typing methods are based on the sequences of $\mathrm{fliC}$ gene that encode for the FliC, the flagellar filament structural protein (Wang et al., 2003). The $\mathrm{N}$ - and C-terminals of FliC are highly conserved, so different $\mathrm{H}$-types are due to amino acid differences within the central region, which is the surfaceexposed antigenic part of the flagellar filament (Namba et al., 1989). Thus, PCR methods developed to distinguish H-types target the variable region of the fliC gene (Machado et al., 2000); however, these regions of some H-types such as H1 and $\mathrm{H} 12$ and $\mathrm{H} 25$ and $\mathrm{H} 28$ are very similar, making them difficult to distinguish. However, a two-step PCR method was developed that can distinguish between $f_{i i C} \mathrm{H} 1$ and $\mathrm{fliC}_{\mathrm{H} 12}$ (Beutin et al., 2015, 2016). Other methods such as MatrixAssisted Laser Desorption/Ionization Time-of-Flight (MALDITOF)-based peptide mass fingerprinting in conjunction with a custom E. coli H-antigen data base (Cheng et al., 2014) has been also utilized to distinguish H-types (Chui et al., 2015).

\section{METHODS USED FOR SUBTYPING AND MOLECULAR SEROTYPING OF E. coli}

Subtyping methods that allow for differentiation of $E$. coli beyond the species and subspecies level are critical for determining the source of outbreaks and establishing transmission pathways (Eppinger et al., 2011; Frank et al., 2011). Several phenotypebased and genotype-based methods for subtyping E. coli are listed in Table 1. Phenotypic culture methods, in conjunction with biochemical-based testing, serotyping, phage typing, multilocus enzyme electrophoresis have been used for many years and could be considered gold standard methods; however, they are time and labor intensive and may not be very discriminatory.

Compared to phenotypic methods, genetic subtyping methods that are based on bacterial DNA, generally have better discriminatory ability. Of the various methods used for E. coli subtyping, PFGE is a reliable and highly discriminating method and has been considered to be the "gold standard" of typing methods. Through the establishment of PulseNet (Ribot et al., 2006), use of PFGE has had a major impact on pathogen subtyping and outbreak investigation.

In contrast to traditional serotyping, Luminex ${ }^{\circledR}$-based suspension assays allow for simultaneous testing for multiple serogroups in a single assay. Lin et al. (2011) performed PCR assays targeting the $w z x$ and $w z y$ genes of ten Shiga toxin-producing E. coli (STEC) serogroups, and then used the Luminex $^{\circledR}$ system to identify the 10 serogroups through binding of the PCR products to fluorescent microspheres conjugated to specific DNA probes for each of the ten serogroups. Clotilde et al. (2015) used the Luminex ${ }^{\circledR}$ technology, both antibody- and multiplex PCR-based, and compared them to traditional E. coli serotyping. The results of the two Luminex ${ }^{\circledR}$ assays were mostly consistent, and 11 STEC isolates that were previously untypeable by traditional serotyping were able to be typed.

Multiplex PCR-based assays targeting unique regions within the E. coli O-AGCs have been used to determine the O-groups. A review by DebRoy et al. (2011) describes many of these assays, most of which target the E. coli wzx and wzy genes. Based on O-AGC sequence data for all O-groups, Iguchi et al. (2015b) designed 162 PCR primer pairs for identification and classification of E. coli O-serogroups. The primer pairs were 
TABLE 1 | Phenotype- and genotype-based methods for subtyping and molecular serotyping of $E$. coli.

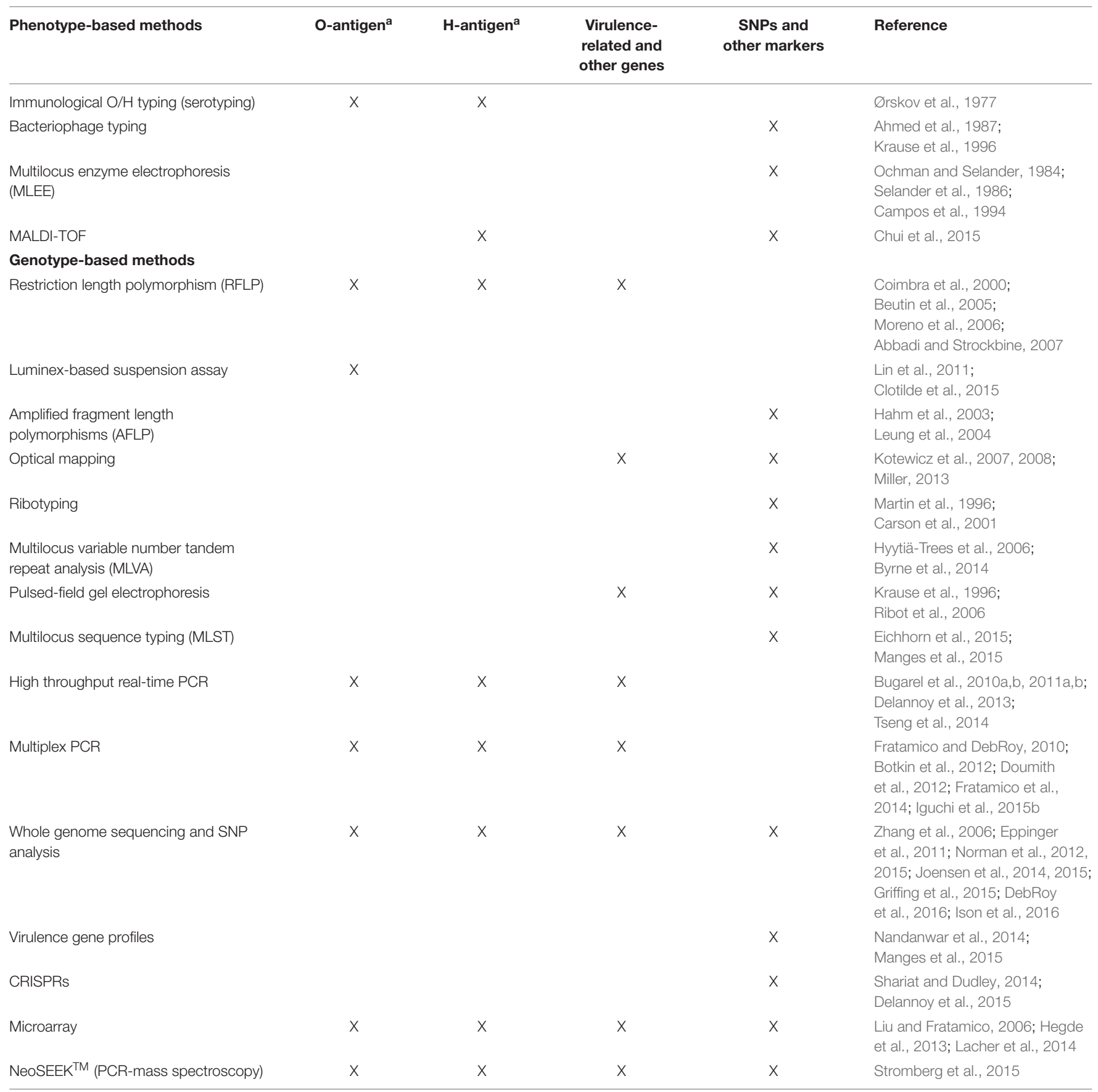

${ }^{a}$ The O-somatic and $\mathrm{H}$-flagellar antigens define the $\mathrm{E}$. coli serotype. Agglutination assays using antibodies that react with the specific $\mathrm{O}$-and $\mathrm{H}$-antigens are the basis for traditional serotyping. Molecular serotyping methods are generally based on genetic targets specific to the $\mathrm{O}$ - and $\mathrm{H}$-antigens.

used in 20 separate multiplex PCR assays with each assay containing 6-9 primer pairs that amplified products of different sizes so that they could be distinguished. A high-throughput PCR method based on the GeneDisc ${ }^{\circledR}$ array targeted virulence genes and $\mathrm{O}$ - and $\mathrm{H}$-type-specific genes for identification of STEC associated with severe illness (Bugarel et al., 2010b). Another high-throughput method, known as the BioMark ${ }^{\mathrm{TM}}$ real-time PCR system (Fluidigm), used a panel of virulence genes as discriminative markers to differentiate EHEC O26 strains,
EHEC-like O26 pathogenic strains, and avirulent O26 strains (Bugarel et al., 2011a).

Clustered regularly interspaced short palindromic repeats (CRISPR) are short, highly conserved DNA repeats separated by unique sequences of similar length, and they have been used for subtyping, identification, and detection of bacteria (Shariat and Dudley, 2014). Based on spacer content or sequencing of CRISPR loci, CRISPR-based typing analyses can be used to differentiate strains for epidemiological investigations or 
for detection. Delannoy et al. (2012) utilized CRISPR loci of seven important EHEC serotypes to develop real-time PCR assays, generating results based on CRISPR polymorphisms that correlated with specific EHEC O:H serotypes and the presence of EHEC virulence genes.

DNA microarrays have also been developed for molecular serotyping of E. coli (Liu and Fratamico, 2006; Ballmer et al., 2007; Geue et al., 2014; Lacher et al., 2014). One microarray method to identify E. coli serogroups involved spotting O-groupspecific $w z x$ or $w z y$ gene oligonucleotides or PCR products onto the chip and hybridized with labeled PCR products of the entire O-AGCs (Liu and Fratamico, 2006). Lacher et al. (2014) reported on the use of an FDA-ECID (E. coli identification) microarray for $\mathrm{O}$ - and H-typing of E. coli. The ECID chip was designed based on $>250$ E. coli genomes and incorporates over 40,000 E. coli genes, including $\mathrm{O}$ - and $\mathrm{H}$-group-specific genes, and approximately 9800 single nucleotide polymorphisms (SNPs). Antibody-based microarrays have also been developed to detect important nonO157 STEC serogroups (Gehring et al., 2013; Hegde et al., 2013). Although this method is rapid and has the potential to be used for high throughput screening, the utilization of this method is dependent on the availability of antibodies with good specificity.

The commercial introduction of next-generation sequencing technologies has made it possible to perform routine WGS of E. coli and other bacteria relatively rapidly and at affordable costs (Franz et al., 2014). Since WGS typing has discriminatory power superior to other typing methods, it has the potential to revolutionize bacterial subtyping. A MLST webserver was designed to determine sequence types (STs) of bacteria using WGS data. STs were determined from uploaded preassembled complete or partial genome sequences or short sequence reads obtained from different sequencing platforms (Larsen et al., 2012). Based on SNPs observed from WGS data, Norman et al. (2015) identified unique STEC O26 genotypes in human and cattle strains. These isolates had similar virulence gene profiles and did not cluster in separate polymorphism-derived genotypes, and thus human and cattle strains could not be distinguished within the phylogenetic clusters. An approach based on targeted amplicon sequencing for SNP genotyping was used to determine the relationship of stx-positive and stxnegative E. coli O26:H11 strains from cattle compared to the genomes of human clinical isolates (Ison et al., 2016). Joensen et al. (2015) described SerotypeFinder, a publicly available web tool hosted by the Center for Genomic Epidemiology, Denmark, which enables WGS-based serotyping of E. coli. Typing is based on $w z x, w z y, w z m$, and $w z t$, as well as flagellinassociated genes. Similar to SerotypeFinder, the VirulenceFinder tool can be used to determine virulence genes in $E$. coli to determine different pathogenic groups (Joensen et al., 2014).

Whole genome sequencing typing has the potential to be the new "gold-standard" for pathogen subtyping. However, some challenges need to be addressed before standardization and full implementation of this technology. The bioinformatic analyses required to analyze enormous amounts of sequence data generated by WGS are necessitating the development of analysis pipelines to enhance the assembly, annotation, and interpretation of the data, which will require a coordinated international approach (Franz et al., 2014; Oulas et al., 2015). Currently, the following databases for WGS and advanced detection are available: the $100 \mathrm{~K}$ Genome Project ${ }^{1}$, GenomeTrakr Network $^{2}$, Global Microbial Identifier ${ }^{3}$, and Advanced Molecular Detection $^{4}$. These databases are creating a vast resource of microbial genome information for WGS-based surveillance of microbial pathogens. Furthermore, detailed analysis of WGS data can determine the E. coli $\mathrm{O}$ - and H-type and provide information on the resistome (antibiotic resistance gene profile) of the isolate, and the presence of specific virulence genes, prophages, and plasmids, as well as other genetic information important to identify $E$. coli pathotypes as well as utility in evolutionary studies. The advantages of WGS approaches are being recognized by academic, government, industry, and the private sector for addressing regulatory and public health needs. However, as we move toward the use of these genetic approaches for non-culture-based detection, characterization, subtyping, trace backs, and outbreak investigations, it will be critical to establish bioinformatics pipelines that are capable of analyzing and handling the large amounts of data that are generated.

\section{AUTHOR CONTRIBUTIONS}

PF, CD, YL, DN, GB, and PF have made a substantial, direct, and intellectual contribution to the work and approved it for publication.

\section{FUNDING}

This work was supported in part by an appointment to the Agricultural Research services (ARS) Research Participation Program which is administered by the Oak Ridge Institute for Science and Education (ORISE) through an interagency agreement between the U.S. Department of Energy (DOE) and the USDA. ORISE is managed by ORAU under DOE contract number DE-AC05-06OR23100. All opinions expressed in this manuscript are the author's and do not necessarily reflect the policies and views of USDA, ARS, DOE, or ORAU/ORISE.

\footnotetext{
${ }^{1}$ http://100kgenome.vetmed.ucdavis.edu/

${ }^{2}$ http://www.fda.gov/Food/FoodScienceResearch/WholeGenomeSequencing ProgramWGS/

${ }^{3}$ http://www.cdc.gov/amd/project-summaries/index.html

${ }^{4} \mathrm{http} / / /$ www.globalmicrobialidentifier.org/
} 


\section{REFERENCES}

Abbadi, S. H., and Strockbine, N. A. (2007). Identification of Escherichia coli flagellar types by restriction of the amplified fliC gene. Egypt. J. Med. Microbiol. $16,225-233$

Ahmed, R., Bopp, C., Borczyk, A., and Kasatiya, S. (1987). Phage-typing scheme for Escherichia coli O157:H7. J. Infect. Dis. 155, 806-809. doi: 10.1093/infdis/155.4.806

Ballmer, K., Korczak, B. M., Kuhnert, P., Slickers, P., Ehricht, R., and Hächler, H. (2007). Fast DNA serotyping of Escherichia coli by use of an oligonucleotide microarray. J. Clin. Microbiol. 45, 370-379. doi: 10.1128/JCM. 01361-06

Beutin, L., Delannoy, S., and Fach, P. (2015). Sequence variations in the flagellar antigen genes fliCH25 and fliCH28 of Escherichia coli and their use in identification and characterization of enterohemorrhagic E. coli (EHEC) O145:H25 and O145:H28. PLOS ONE 10:e0126749. doi: 10.1371/journal.pone.0126749

Beutin, L., Delannoy, S., and Fach, P. (2016). Genetic analysis and detection of fliCH1 and fliCH12 genes coding for serologically closely related flagellar antigens in human and animal pathogenic Escherichia coli. Front. Microbiol. 7:135. doi: 10.3389/fmicb.2016.00135

Beutin, L., Strauch, E., Zimmermann, S., Kaulfuss, S., Schaudinn, C., Männel, A., et al. (2005). Genetical and functional investigation of fliC genes encoding flagellar serotype $\mathrm{H} 4$ in wildtype strains of Escherichia coli and in a laboratory E. coli K-12 strain expressing flagellar antigen type H48. BMC Microbiol. 5:4. doi: 10.1186/1471-2180-5-4

Botkin, D. J., Galli, L., Sankarapani, V., Soler, M., Rivas, M., and Torres, A. G. (2012). Development of a multiplex PR assay for detection of Shiga toxinproducing Escherichia coli, enterohemorrhagic E. coli, and enteropathogenic E. coli strains. Front. Cell Infect. Microbiol. 2:8. doi: 10.3389/fcimb.2012.00008

Bugarel, M., Beutin, L., and Fach, P. (2010a). Low-density macroarray targeting non-locus of enterocyte effacement effectors (nle genes) and major virulence factors of Shiga toxin-producing Escherichia coli (STEC): a new approach for molecular risk assessment of STEC isolates. Appl. Environ. Microbiol. 76, 203-211. doi: 10.1128/AEM.01921-09

Bugarel, M., Beutin, L., Martin, A., Gill, A., and Fach, P. (2010b). Microarray for the identification of Shiga toxin-producing Escherichia coli (STEC) seropathotypes associated with hemorrhagic colitis and hemolytic uremic syndrome in humans. Int. J. Food Microbiol. 142, 318-329. doi: 10.1016/j.ijfoodmicro.2010.07.010

Bugarel, M., Beutin, L., Scheutz, F., Loukiadis, E., and Fach, P. (2011a). Identification of genetic markers for differentiation of Shiga toxin-producing, enteropathogenic and avirulent strains of Escherichia coli O26. Appl. Environ. Microbiol. 77, 2275-2281. doi: 10.1128/AEM.02832-10

Bugarel, M., Martin, A., Fach, P., and Beutin, L. (2011b). Virulence gene profiling of enterohemorrhagic (EHEC) and enteropathogenic (EPEC) Escherichia coli strains: a basis of molecular risk assessment of typical and atypical EPEC strains. BMC Microbiol. 11:142. doi: 10.1186/1471-2180-11-142

Byrne, L., Elson, R., Dallman, T. J., Perry, N., Ashton, P., Wain, J., et al. (2014). Evaluating the use of multilocus variable number tandem repeat analysis of Shiga toxin-producing Escherichia coli $\mathrm{O} 157$ as a routine public health tool in England. PLoS ONE 9:e85901. doi: 10.1371/journal.pone.0085901

Campos, L. C., Whittam, T. S., Gomes, T. A. T., Andrade, J. R. C., and Trabulsi, L. R. (1994). Escherichia coli serogroup O111 includes several clones of diarrheagenic strains with different virulence properties. Infect. Immun. 62, 3282-3288.

Carson, C. A., Shear, B. L., Ellersieck, M. R., and Asfaw, A. (2001). Identification of fecal Escherichia coli from humans and animals by ribotyping. Appl. Environ. Microbiol. 67, 1503-1507. doi: 10.1128/AEM.67.4.1503-1507.2001

Centers for Disease Control and Prevention [CDC] (1999). Laboratory Methods for the Diagnosis of Epidemic Dysentery and Cholera. Available at: http://www.cdc.gov/cholera/pdf/Laboratory-Methods-for-the-Diagnosis-o f-Epidemic-Dysentery-and-Cholera.pdf [Accessed 14 February, 2016].

Cheng, K., Sloan, A., McCorrister, S., Babiuk, S., Bowden, T. R., Wang, G., et al. (2014). Fit-for-purpose curated database application in mass spectrometrybased targeted protein identification and validation. BMC Res. 7:444. doi: 10.1186/1756-0500-7-444

Chui, H., Chan, M., Hernandez, D., Chong, P., McCorrister, S., Robinson, A., et al. (2015). Rapid, sensitive and specific E. coli $\mathrm{H}$ antigen typing by matrix-assisted laser desorption/ionization time-of-flight (MALDI-TOF)-based peptide mass fingerprinting. J. Clin. Microbiol. 53, 2480-2485. doi: 10.1128/JCM.00593-15

Clermont, O., Bonacorsi, S., and Bingen, E. (2000). Rapid and simple determination of the Escherichia coli phylogenetic group. Appl. Environ. Microbiol. 66, 4555-4558. doi: 10.1128/AEM.66.10.4555-4558.2000

Clotilde, L. M., Salvador, A., Bernard, C. I. V., Lin, A., Lauzon, C., Muldoon, M., et al. (2015). Comparison of multiplex immunochemical and molecular serotyping methods for Shiga toxin-producing Escherichia coli. Foodborne Pathog. Dis. 12, 118-121. doi: 10.1089/fpd.2014.1827

Coimbra, R. S., Grimont, F., Lenormand, P., Burguière, Beutin, L., and Grimont, P. A. D. (2000). Identification of Escherichia coli O-serogroups by restriction of the amplified O-antigen gene cluster (rfp-RFLP). Res. Microbiol. 151, 639-654. doi: 10.1016/S0923-2508(00)00134-0

DebRoy, C., Fratamico, P. M., Yan, X., Baranzoni, G. M., Liu, Y., Needleman, D. S., et al. (2016). Comparison of O-antigen gene clusters of all O-serogroups of Escherichia coli and proposal for adopting a new nomenclature for O-typing. PLoS ONE 11:e0147434. doi: 10.1371/journal.pone.0147434

DebRoy, C., Roberts, E., and Fratamico, P. M. (2011). Detection of O antigens in Escherichia coli. Anim. Health Res. Rev. 12, 169-185. doi: $10.1017 /$ S1466252311000193

Delannoy, S., Beutin, L., and Fach, P. (2013). Discrimination of enterohemorrhagic Escherichia coli (EHEC) from non-EHEC strains based on detection of various combinations of type III effector genes. J. Clin. Microbiol. 51, 3257-3262. doi: 10.1128/JCM.01471-13

Delannoy, S., Beutin, L., and Fach, P. (2015). Improved traceability of Shiga-toxinproducing Escherichia coli using CRISPRs for detection and typing. Environ. Sci. Pollut. Res. Int. 1-12. doi: 10.1007/s11356-015-5446-y

Delannoy, S., Beutin, R., and Fach, P. (2012). Use of clustered regularly interspaced short palindromic repeat sequence polymorphism for specific detection of enterohemorrhagic Escherichia coli strains of serotypes O26:H11, O45:H2, O103:H2, O111:H8, O121:H19, O145:H28, and O157:H7 by real-time PCR. J. Clin. Microbiol. 50, 4035-4040.

Doumith, M., Day, M. J., Hope, R., Wain, J., and Woodford, N. (2012). Improved multiplex PCR strategy for rapid assignment of the four major Escherichia coli phylogenetic groups. J. Clin. Microbiol. 50, 3108-3110. doi: 10.1128/JCM.01468-12

Eichhorn, I., Heidemanns, K., Semmler, T., Kinnemann, B., Mellmann, A., Harmsen, D., et al. (2015). Highly virulent non-O157 enterohemorrhagic Escherichia coli (EHEC) serotypes reflect similar phylogenetic lineages, providing new insights into the evolution of EHEC. Appl. Environ. Microbiol. 81, 7041-7047. doi: 10.1128/AEM.01921-15

Eppinger, M., Mammel, M. K., Leclerc, J. E., Ravel, J., and Cebula, T. A. (2011). Genetic anatomy of Escherichia coli O157:H7 outbreaks. Proc. Natl. Acad. Sci. U.S.A. 108, 20142-20147. doi: 10.1073/pnas.1107 176108

Ewing, W. H. (1986). Edwards and Ewing's Identification of the Enterobacteriaceae. Int. J. Syst. Evol. Microbiol. 36, 581-582.

Frank, C., Werber, D., Jakob, C. J., Askar, M., Faber, M., der Heiden, M., et al. (2011). Epidemic profile of Shiga toxin-producing Escherichia coli O104:H4 outbreak in Germany. N. Engl. J. Med. 365, 1771-1780.

Franz, E., Delaquis, P., Morabito, S., Beutin, L., Gobius, K., Rasko, D. A., et al. (2014). Exploiting the explosion of information associated with whole genome sequencing to tackle Shiga toxin-producing Escherichia coli (STEC) in global food production systems. Int. J. Food Microbiol. 187, 57-72. doi: 10.1016/j.ijfoodmicro.2014.07.002

Fratamico, P. M., and DebRoy, C. (2010). Detection of Escherichia coli O157:H7 in food using real-time multiplex PCR assays targeting the stx1, stx2, wzyO157, and the fliCh7 or eae genes. Food Anal. Methods 3, 330-337. doi: 10.1007/s12161-010-9140-x

Fratamico, P. M., Wasilenko, J. L., Garman, B., DeMarco, D. R., Varkey, S., Jensen, M., et al. (2014). Evaluation of a multiplex PCR real-time PCR method for detecting Shiga toxin-producing Escherichia coli in beef and comparison to the U.S. Department of Agriculture Food Safety and Inspection Service Microbiology Laboratory Guidebook Method. J. Food Prot. 77, 180-188. doi: 10.4315/0362-028X.JFP-13-248

Gehring, A., Barnett, C., Chu, T., DebRoy, C., D’Souza, D., Eaker, S., et al. (2013). A high-throughput antibody-based microarray typing platform. Sensors (Basel) 13, 5737-5748. doi: 10.3390/s130505737 
Geue, L., Monecke, S., Engelmann, I., Braun, S., Slickers, P., and Ehricht, R. (2014). Rapid microarray-based DNA genoserotyping of Escherichia coli. Microbiol. Immunol. 58, 77-86. doi: 10.1111/1348-0421.12120

Greenfield, L. K., and Whitfield, C. (2012). Synthesis of lipopolysaccharide O-antigens by ABC transporter-dependent pathways. Carbohydr. Res. 356, 12-24. doi: 10.1016/j.carres.2012.02.027

Griffing, S. M., MacCannell, D. R., Schmidtke, A. J., Freeman, M. M., HyytiäTrees, E., Gerner-Smidt, P., et al. (2015). Canonical single nucleotide polymorphisms (SNPs) for high-resolution subtyping of Shiga-toxin producing Escherichia coli (STEC) O157: H7. PLoS ONE 10:e0131967. doi: 10.1371 /journal.pone. 0131967

Hahm, B.-K., Maldonado, Y., Schreiber, E., Bhunia, A. K., and Nakatsu, C. H. (2003). Subtyping of foodborne and environmental isolates of Escherichia coli by multiplex-PCR, rep-PCR, PFGE, ribotyping and AFLP. J. Microbiol. Methods 53, 387-399. doi: 10.1016/S0167-7012(02)00259-2

Hegde, N. V., Praul, C., Gehring, A., Fratamico, P., and DebRoy, C. (2013). Rapid O serogroup identification of the six clinically relevant Shiga toxin-producing Escherichia coli by antibody microarray. J. Microbiol. Methods 93, 273-276. doi: 10.1016/j.mimet.2013.03.024

Hobbs, M., and Reeves, P. R. (1994). The JUMPstart sequence: a 39 bp element common to several polysaccharide gene clusters. Mol. Microbiol. 12, 855-856. doi: 10.1111/j.1365-2958.1994.tb01071.x

Hyytiä-Trees, E., Smole, S. C., Fields, P. A., Swaminathan, B., and Ribot, E. M. (2006). Second generation subtyping: a proposed PulseNet protocol for multiple-locus variable-number tandem repeat analysis of Shiga toxinproducing Escherichia coli O157 (STEC O157). Foodborne Pathog. Dis. 3, 118-131. doi: 10.1089/fpd.2006.3.118

Iguchi, A., Iyoda, S., Kikuchi, T., Ogura, Y., Katsura, K., Ohnishi, M., et al. (2015a). A complete view of the genetic diversity of the Escherichia coli $\mathrm{O}$-antigen biosynthesis gene cluster. DNA Res. 22, 101-107. doi: 10.1093/dnares/dsu043

Iguchi, A., Iyoda, S., Seto, K., Morita-Ishihara, T., Sheutz, F., Ohnishi, M., et al. (2015b). Escherichia coli O-genotyping PCR: a comprehensive and practical platform for molecular O serogrouping. J. Clin. Microbiol. 53, 2427-2432.

Ison, S. A., Delannoy, S., Bugarel, M., Nagaraja, T. G., Renter, D. G., Den Bakker, H. C., et al. (2016). ). Targeted amplicon sequencing for singlenucleotide-polymorphism genotyping of attaching and effacing Escherichia coli O26:H11 cattle strains via a high-throughput library preparation technique. Appl. Environ. Microbiol. 82, 640-649. doi: 10.1128/JCM.00321-15

Joensen, K. G., Scheutz, F., Lund, O., Hasman, H., Kaas, R. S., Nielsen, E. M., et al. (2014). Real-time whole-genome sequencing for routine typing, surveillance, and outbreak detection of verotoxigenic Escherichia coli. J. Clin. Microbiol. 52, 1501-1510.

Joensen, K. G., Tetzschner, A. M., Iguchi, A., Aarestrup, F. M., and Scheutz, F. (2015). Rapid and easy in silico serotyping of Escherichia coli using whole genome sequencing (WGS) data. J. Clin. Microbiol. 53, 2410-2426. doi: 10.1128/JCM.00008-15

Kaper, J. B., Nataro, J. P., and Mobley, H. L. (2004). Pathogenic Escherichia coli. Nat. Rev. Microbiol. 2, 123-140. doi: 10.1038/nrmicro818

Kaufmann, F. (1943). Ueber neue thermolabile Körperantigen der Colibakterien. Acta Pathol. Microbiol. Scand. 20, 21-44.

Kaufmann, F. (1944). Zur serologie der coli-gruppe. Acta Pathol. Microbiol. Scand. 21, 20-45. doi: 10.1111/j.1699-0463.1944.tb00031.x

Kaufmann, F. (1947). The serology of E. coli group. J. Immunol. 57, 71-100.

Kotewicz, M. L., Jackson, S. A., LeClerc, J. E., and Cebula, T. A. (2007). Optical maps distinguish individual strains of Escherichia coli O157:H7. Microbiology 153, 1720-1733. doi: 10.1099/mic.0.2006/004507-0

Kotewicz, M. L., Mammel, M. K., LeClerc, J. E., and Cebula, T. A. (2008). Optical mapping and 454 sequencing of Escherichia coli O157:H7 isolates linked to the US 2006 spinach-associated outbreak. Microbiology 154, 3518-3528. doi: 10.1099/mic.0.2008/019026-0

Krause, U., Thomson-Carter, F. M., and Pennington, T. H. (1996). Molecular epidemiology of Escherichia coli O157:H7 by pulsed-field gel electrophoresis and comparison with that by bacteriophage typing. J. Clin. Microbiol. 34, 959-961.

Lacher, D. W., Gangiredla, J., Jackson, S. A., Elkins, C. A., and Feng, P. C. (2014). Novel microarray design for molecular serotyping of Shiga toxin- producing Escherichia coli strains isolated from fresh produce. Appl. Environ. Microbiol. 80, 4677-4682. doi: 10.1128/AEM.01049-14
Larsen, M. V., Cosentino, S., Rasmussen, S., Friis, C., Hasman, H., Marvig, R. L., et al. (2012). Multilocus sequence typing of total-genome-sequenced bacteria. J. Clin. Microbiol. 50, 1355-1361. doi: 10.1128/JCM.06094-11

Leung, K. T., Mackereth, R., Tien, Y.-C., and Topp, E. (2004). A comparison of AFLP and ERIC-PCR analyses for discriminating Escherichia coli from cattle, pig and human sources. FEMS Microbiol. Ecol. 47, 111-119. doi: 10.1016/S01686496(03)00254-X

Lin, A., Nguyen, L., Lee, T., Clotilde, L. M., Kase, J. A., Son, I., et al. (2011). Rapid O serogroup identification of the ten most clinically relevant STECs by Luminex microbead-based suspension array. J. Microbiol. Methods 87, 105-110. doi: 10.1016/j.mimet.2011.07.019

Liu, B., Knirel, Y. A., Feng, L., Perepelov, A. V., Senchenkova, S. N., Reeves, P. R., et al. (2014). Structural diversity in Salmonella $\mathrm{O}$ antigens and its genetic basis. FEMS Microbiol. Rev. 38, 56-89. doi: 10.1111/1574-6976.12034

Liu, B., Knirel, Y. A., Feng, L., Perepelov, A. V., Senchenkova, S. N., Wang, Q., et al. (2008). Structure and genetics of Shigella O antigens. FEMS Microbiol. Rev. 32, 627-653. doi: 10.1111/j.1574-6976.2008.00114.x

Liu, Y., and Fratamico, P. (2006). Escherichia coli O antigen typing using DNA microarrays. Mol. Cell Probes 20, 239-244. doi: 10.1016/j.mcp.2006.01.001

Liu, Y., Fratamico, P., Debroy, C., Bumbaugh, A. C., and Allen, J. W. (2008). DNA sequencing and identification of serogroup-specific genes in the Escherichia coli $\mathrm{O} 118 \mathrm{O}$ antigen gene cluster and demonstration of antigenic diversity but only minor variation in DNA sequence of the $\mathrm{O}$ antigen clusters of $E$. coli $\mathrm{O} 118$ and O151. Foodborne Pathog. Dis. 5, 449-457. doi: 10.1089/fpd.2008.0096

Liu, Y., Yan, X., DebRoy, C., Fratamico, P. M., Needleman, D. S., Li, R. W., et al. (2015). Escherichia coli O-antigen gene clusters of serogroups O62, O68, O131, O140, O142, and O163: DNA sequences and similarity between O62 and O68, and PCR-based serogrouping. Biosensors (Basel) 5, 51-68. doi: 10.3390/bios5010051

Machado, J., Grimont, F., and Grimont, P. A. D. (2000). Identification of Escherichia coli flagellar types by restriction of the amplified fliC gene. Res. Microbiol. 151, 535-546. doi: 10.1016/S0923-2508(00)00223-0

Manges, A. R., Harel, J., Masson, L., Edens, T. J., Portt, A., Reid-Smith, R. J., et al. (2015). Multilocus sequence typing and virulence gene profiles associated with Escherichia coli from human and animal sources. Foodborne Pathog. Dis. 12, 302-310. doi: $10.1089 /$ fpd.2014.1860

Manges, A. R., and Johnson, J. R. (2012). Food-borne origins of Escherichia coli causing extraintestinal infections. Clin. Infect. Dis. 55, 712-718. doi: $10.1093 /$ cid/cis502

Martin, I. E., Tyler, S. D., Tyler, K. D., Khakhria, R., and Johnson, W. M. (1996). Evaluation of ribotyping as epidemiologic tool for typing Escherichia coli serogroup O157 isolates. J. Clin. Microbiol. 34, 720-723.

Miller, J. M. (2013). Whole-genome mapping: a new paradigm in strain-typing technology. J. Clin. Microbiol. 51, 1066-1070. doi: 10.1128/JCM.00093-13

Mitchell, N. M., Johnson, J. R., Johnston, B., Curtis, R. III, and Mellata, M. (2015). Zoonotic potential of Escherichia coli isolates from retail chicken meat products and eggs. Appl. Environ. Microbiol. 81, 1177-1187. doi: 10.1128/AEM.03524-14

Moreno, A. C. R., Guth, B. E. C., and Martinez, M. B. (2006). Can the fliC PCRrestriction fragment length polymorphism technique replace classic serotyping methods for characterizing the $\mathrm{H}$ antigen of enterotoxigenic Escherichia coli strains? J. Clin. Microbiol. 44, 1453-1458. doi: 10.1128/JCM.44.4.14531458.2006

Namba, K., Yamashita, I., and Vonderviszt, F. (1989). Structure of the core and central channel of bacterial flagella. Nature 342, 648-654. doi: 10.1038/342648a0

Nandanwar, N., Janssen, T., Kühl, M., Ahmed, N., Ewers, C., and Wieler, L. H. (2014). Extraintestinal pathogenic Escherichia coli (ExPEC) of huan and avian origin belonging to sequence type complex 95 (STC95) portray indistinguishable virulence features. Int. J. Med. Microbiol. 304, 835-842. doi: 10.1016/j.ijmm.2014.06.009

Nordstrom, L., Liu, C. M., and Price, L. B. (2013). Foodborne urinary tract infections: a new paradigm for antimicrobial-resistant foodborne illness. Front. Microbiol. 4:29. doi: 10.3389/fmicb.2013.00029

Norman, K. N., Clawson, M. L., Strockbine, N. A., Mandrell, R. E., Johnson, R., Ziebell, K., et al. (2015). Comparison of whole genome sequences from human and non-human Escherichia coli O26 strains. Front. Cell Infect. Microbiol. 5:21. doi: 10.3389/fcimb.2015.00021

Norman, K. N., Strockbine, N. A., and Bono, J. L. (2012). Association of nucleotide polymorphisms within the O-antigen gene cluster of Escherichia coli O26, O45, 
O103, O111, O121, and O145 with serogroups and genetic subtypes. Appl. Environ. Microbiol. 78, 6689-6703. doi: 10.1128/AEM.01259-12

Ochman, H., and Selander, R. K. (1984). Standard reference strains of Escherichia coli from natural populations. J. Bacteriol. 157, 690-693.

Ørskov F., and Ørskov I. (1984). "Serotyping of Escherichia coli," in Methods in Microbiology, Vol. 14, ed. T. Bergan (London: Academic Press), 43-112.

Ørskov, F. I, Ørskov, F., Bettelheim, K. A., and Chandler, M. E. (1975). Two new Escherichia coli $\mathrm{O}$ antigens, $\mathrm{O} 162$ and $\mathrm{O} 163$, and one new $\mathrm{H}$ antigen, H56. Withdrawal of H antigen H50. Acta Pathol. Microbiol. Scand. 83, 121-124.

Ørskov, I., Ørskov, F., Jann, B., and Jann, K. (1977). Serology, chemistry, and genetics of $\mathrm{O}$ and $\mathrm{K}$ antigens of Escherichia coli. Bacteriol. Rev. 41, 667-710.

Oulas, A., Pavloudi, C., Polymenakou, P., Pavlopoulos, G. A., Papanikolaou, N., Kotoulas, G., et al. (2015). Metagenomics: tools and insights for analyzing nextgeneration sequencing data derived from biodiversity studies. Bioinformat. Biol. Insights 9, 75-88. doi: 10.4137/BBI.S12462

Ribot, E. M., Fair, M. A., Gautom, R., Cameron, D. N., Hunter, S. B., Swaminathan, B., et al. (2006). Standardization of pulsed-field gel electrophoresis protocols for the subtyping of Escherichia coli O1 57:H7, Salmonella, and Shigella for PulseNet. Foodborne Pathog. Dis. 3, 59-67. doi: 10.1089/fpd.2006.3.59

Russo, T. A., and Johnson, J. R. (2003). Medical and economic impact of extraintestinal infections due to Escherichia coli: focus on an increasingly important endemic problem. Microbes Infect. 5, 449-456. doi: 10.1016/S12864579(03)00049-2

Samuel, G., and Reeves, P. (2003). Biosynthesis of O-antigens: genes and pathways involved in nucleotide sugar precursor synthesis and $\mathrm{O}$-antigen assembly. Carbohydr. Res. 338, 2503-2519. doi: 10.1016/j.carres.2003.07.009

Sarkar, S., Ulett, G. C., Totsika, M., Phan, M.-D., and Schembri, M. A. (2014). Role of capsule and $\mathrm{O}$ antigen in the virulence of uropathogenic Escherichia coli. PLoS ONE 9:e94786. doi: 10.1371/journal.pone.0094786

Scheutz, F., Cheasty, T., Woodward, D., and Smith, H. R. (2004). Designation of O174 and O175 to temporary O groups OX3 and OX7, and six new E. col O groups that include verocytotoxin-producing E. coli (VTEC):O176, O177, O178, O179, O180 and O181. APMIS. 2004, 569-584.

Selander, R. K., Caugant, K. A., Ochman, H., Musser, J. M., Gilmour, M. N., and Whittam, T. S. (1986). Methods of multilocus enzyme electrophoresis for bacterial population genetics and systematics. Appl. Environ. Microbiol. 51, 873-884.

Shariat, N., and Dudley, E. G. (2014). CRISPRs: molecular signatures used for pathogen subtyping. Appl. Environ. Microbiol. 80, 430-439. doi: 10.1128/AEM.02790-13
Singer, R. S. (2015). Urinary tract infections attributed to diverse ExPEC strains in food animals: evidence and data gaps. Front. Microbiol. 6:28. doi: 10.3389/fmicb.2015.00028

Smith, J. L., Fratamico, P. M., and Gunther, N. (2007). Extraintestinal pathogenic Escherichia coli (ExPEC). Foodborne Pathog. Dis. 4, 134-163. doi: 10.1089/fpd.2007.0087

Stromberg, Z. R., Baumann, N. W., Lewis, G. L., Sevart, N. J., Cernicchiaro, N., Renter, D. G., et al. (2015). Prevalence of enterohemorrhagic Escherichia coli O26, O45, O103, O111, O121, O145, and O157 on hides and preintervention carcass surfaces of feedlot cattle at harvest. Foodborne Pathog. Dis. 12, 631-638. doi: $10.1089 /$ fpd.2015.1945

Tseng, M., Fratamico, P., Bagi, L., Delannoy, S., Fach, P., Manning, S., et al. (2014). Diverse virulence gene content of Shiga toxin-producing Escherichia coli from finishing swine. Appl. Environ. Microbiol. 80, 6395-6402. doi: 10.1128/AEM.01761-14

Vincent, C., Boerlin, P., Daignault, D., Dozois, C. M., Dutil, L., Galanakis, C., et al. (2010). Food reservoir for Escherichia coli causing urinary tract infections. Emerg. Infect. Dis. 16, 88-95. doi: 10.3201/eid1601. 091118

Wang, L., Rothemund, D., Curd, H., and Reeves, P. R. (2003). Species-wide variation in the Escherichia coli flagellin (H-antigen) gene. J. Bacteriol. 185, 2936-2943. doi: 10.1128/JB.185.9.2936-2943.2003

Wang, W., Perepelov, A. V., Feng, L., Shevelev, S. D., Wang, Q., Senchenkova, S. N., et al. (2007). A group of Escherichia coli and Salmonella enterica O antigens sharing a common backbone structure. Microbiology 153, 2159-2167.

Zhang, W., Qi, W., Albert, T. J., Motiwala, A. S., Alland, D., Hyytia-Trees, E. K., et al. (2006). Probing genomic diversity and evolution of Escherichia coli $\mathrm{O} 157$ by single nucleotide polymorphisms. Genome Res. 16, 757-767. doi: $10.1101 /$ gr.4759706

Conflict of Interest Statement: The authors declare that the research was conducted in the absence of any commercial or financial relationships that could be construed as a potential conflict of interest.

Copyright (c) 2016 Fratamico, DebRoy, Liu, Needleman, Baranzoni and Feng. This is an open-access article distributed under the terms of the Creative Commons Attribution License (CC BY). The use, distribution or reproduction in other forums is permitted, provided the original author(s) or licensor are credited and that the original publication in this journal is cited, in accordance with accepted academic practice. No use, distribution or reproduction is permitted which does not comply with these terms. 